Pilar Giménez Armentia

Universidad Francisco de Vitoria

@ gimenez.prof@ufv.es (iD 0000-0001-5655-7703

Fernando Viñado Oteo

Universidad Francisco de Vitoria

@ p.f.vinado@ufv.es (iD 0000-0003-2178-1750
Recibido / Received 8 de noviembre de 2021

- Aceptado / Acepted 20 de noviembre de 2021

- Páginas / Pages De la 89 a la 107

- ISSN: 1885-365X

Francisco Javier Gómez Díez

Universidad Francisco de Vitoria

@ j.gomez.profufv.es (iD 0000-0002-5948-6186

\title{
La información en tiempos de crisis: Imagen de la Universidad española durante la pandemia
}

\section{Information in times of crisis: the case of the Spanish University during the pandemic}

\section{RESUMEN:}

La covid-19 ha sido el tema que más espacio ha ocupado en los medios de comunicación de todo el mundo. Podríamos afirmar que ha habido una saturación mediática sin precedentes. Los medios de comunicación han tenido el desafío de informar desde el rigor y la búsqueda de la verdad en una situación de confusión y de crisis jamás vista en los últimos tiempos. El presente artículo pretende mostrar un análisis de la información que ofrecieron los medios sobre la realidad universitaria española durante el estado de alarma. Nos interesaba determinar el tratamiento informativo que la prensa digital española hizo sobre las universidades en España y cuál fue la imagen que reflejó sobre las fortalezas y debilidades de la educación superior durante la pandemia. Para la obtención de este objetivo, se trató de averiguar el grado de importancia que los medios le otorgaron en sus agendas y si hubo o no un discurso dominante por parte de los periódicos españoles. También se analizó si la información que proporcionaron los diarios de mayor difusión se correspondía con la realidad de la situación de la Universidad y sus temas esenciales. Este estudio nos ayudó a concluir la relevancia que obtuvo la educación superior en una situación de crisis como la que hemos vivido y cómo los medios nos transmitieron esa realidad.

\section{PALABRAS CLAVE:}

Covid-19; prensa digital; tratamiento informativo; Universidad; investigación; docencia.

\section{ABSTRACT:}

Covid-19 has been the topic that has occupied the most space in the media around the world. We could say that there has been unprecedented media saturation. The mass media have had the challenge of reporting rigorously and searching for the truth in a situation of confusion and crisis never seen in recent times. This article aims to show an analysis of the information offered by the media about the Spanish university reality, during the state of alarm. We were interested in determining the informational treatment that the Spanish digital press made on the Universities in Spain and what was the image reflected on the strengths and weaknesses of Higher Education during the pandemic. To achieve this objective, an 
attempt was made to find out the degree of importance that the media gave it in their agendas and whether there was a dominant discourse on the part of the Spanish newspapers. It was also analyzed whether the information provided by the most widely circulated newspapers corresponded to the reality of the University situation and its essential issues. This study helped us to conclude the relevance that Higher Education obtained in a crisis such as the one we have experienced and how the media transmitted that reality to us.

KEY WORDS:

Covid-19; digital press; information processing; University; research; teaching.

\section{Introducción}

El trabajo realizado se sostiene y fundamenta sobre la literatura existente en revistas de investigación que tratan estas cuestiones, como es el caso de Beetham (2013), Bucknell (2016), Comunian (2015), De la Torre (2017), Etzkowitz (2018) y Turcan (2016), quienes comparten el papel fundamental que juega la innovación en la educación superior y la idea de que las universidades deben estar abiertas a los cambios culturales y sociales, pero sin olvidar su propósito y fin último. También nos han interesado los trabajos de Barroso (2000), Fernández y Molero (2003), F. J. García (2011), J. A. García (1993), Herranz (2009) y Nieto (2014), que reflejan la imagen que los medios de comunicación muestran sobre la universidad. Y, por último, nos hemos centrado en las investigaciones publicadas en los últimos años sobre el papel y funciones de la prensa digital en España, como son los trabajos de Caminos (2008), Sánchez (2018) y De Cabo (2009).

En este artículo, se ha realizado un análisis pormenorizado de la prensa digital en España y los principales temas que han ocupado las páginas de los periódicos, como la docencia, la investigación, la actuación del Gobierno y el papel de la Universidad durante el estado de alarma. Tras una valoración de la información y teniendo presentes los objetivos que se perseguían, se plantearon las siguientes preguntas: ¿La educación superior fue un asunto relevante para la prensa española?, ¿cuáles fueron los principales temas de interés en la prensa digital acerca de las Universidades?, ¿qué aspectos se destacaron?, ¿cómo valoraron los periódicos el papel de la Universidad en el estado de alarma?, ¿qué enfoque se le dio a la información?, ¿la prensa reflejó los verdaderos temas de preocupación de la Universidad? Para contestar a todos estos interrogantes, se realizó un análisis minucioso de todas las informaciones seleccionadas. Esto dio lugar a una serie de conclusiones, que se expondrán al final del trabajo.

Creemos que este tipo de trabajos, que se realizan en el ámbito académico, son necesarios y pueden dar luz y claridad a una sociedad que ha sido sacudida por una crisis - sanitaria, económica y social- que nos ha hecho ser conscientes de nuestra fragilidad. Hoy más que nunca, es crucial que los académicos asumamos la capacidad que tenemos como institución de ponernos al servicio de la comunidad, en un mundo que demanda respuestas que ayuden a paliar el sufrimiento humano.

La situación que acabamos de vivir con la covid-19 ha puesto de manifiesto la importancia del trabajo interdisciplinar para poner solución a las grandes sombras del desarrollo humano. Los avances en el campo tecnológico se nos presentan como una oportunidad para repensar el proceso de enseñanza universitaria, modificando los roles establecidos hasta ahora. Gracias a estos avances, hemos sido capaces, en la Universidad, de abordar desde una 
normalidad aparente el confinamiento y el estado de alarma al que se ha visto sometida la sociedad española, así como la mayoría de los países. Tras esta crisis, la docencia no solo no se ha visto mermada, sino que nos hemos abierto a un mundo, desconocido para muchos, de oportunidades y posibilidades, con unas herramientas que favorecen y potencian el aprendizaje de nuestros estudiantes.

A su vez, la pandemia también ha mostrado las grandes desigualdades existentes en el desarrollo educativo y en las diferentes instituciones académicas, ya que muchas de ellas no han podido asumir la enseñanza online como hubieran deseado, y muchos estudiantes no han tenido acceso a la docencia por carecer de la tecnología necesaria. La presión que ejerció esta situación sobre estudiantes y profesores ha sido enorme, llevando a un esfuerzo para adaptar las asignaturas a un sistema novedoso que en muchas ocasiones no tuvo una repercusión positiva. Como señalan Tejedor et al., toda esta situación ha puesto de manifiesto la necesidad de una reestructuración de la oferta formativa y la renovación de contenidos que favorezcan tanto la calidad como la equidad en el sistema educativo (2020). El contexto actual se presenta como una oportunidad para la comunidad universitaria para ahondar y profundizar seriamente sobre su papel en la sociedad: en primer lugar, como una institución destinada a educar y formar a sus estudiantes integralmente, capacitándolos para ser pensadores globales, futuros profesionales dispuestos a poner su sabiduría, sus conocimientos y su ciencia no solo al servicio de sí mismos, sino de toda la comunidad; en segundo término, la academia se constituye y conforma como la conciencia crítica de la sociedad, destinada a prestar un servicio de asistencia y ayuda a los sectores más necesitados y desfavorecidos en todos los niveles; y, por último, la Universidad debe forjar y ofrecer los recursos científicos, humanísticos y técnicos que necesita el mundo actual.

La Universidad, desde la docencia, investigación e innovación, debe desempeñar un papel de liderazgo en la transformación de la sociedad, contribuir a la solución de los problemas y fomentar un verdadero desarrollo humano sostenible, ser creadora y difusora de la cultura y asumir un protagonismo esencial para generar soluciones que ayuden a mejorar y a paliar la vulnerabilidad humana. Los medios de comunicación, a su vez, están llamados a informar, formar y dar voz y visibilidad a los diferentes agentes sociales que contribuyen, desde una posición ética, crítica y de servicio, a la mejora de la sociedad.

Tal como hemos expresado, la finalidad de este artículo es ahondar, desvelar y analizar la percepción de los medios sobre las universidades españolas durante el estado de alarma y cómo estos han configurado la opinión pública. Concretamente, nos proponemos los siguientes objetivos:

1. Analizar el tratamiento informativo sobre la educación superior durante el estado de alarma en la prensa digital española.

2. Explorar y señalar los temas de mayor interés para los principales periódicos cuando abordan el tema de la educación superior en tiempos de la covid-19.

3. Analizar el tratamiento en los medios en dos temas claves en el ámbito universitario: la docencia y la investigación.

4. Señalar y resaltar la cabida que han dado los medios a las opiniones de los académicos y rectores sobre el papel de la Universidad española en la pandemia.

5. Intervención de la Universidad en los medios. 


\section{Metodología}

Se ha efectuado una exhaustiva recopilación de las informaciones aparecidas en la prensa digital española desde marzo hasta julio del 2020 en los tres periódicos de mayor difusión: El País, El Mundo y ABC. Para observar el contenido de estos medios, se ha realizado un análisis cuantitativo de todas las noticias publicadas sobre la educación superior. En total, hemos analizado 865 artículos.

\subsection{Selección de LAS fUentes de información}

Para la selección de la prensa, nos guiamos por la clasificación de la AIMC (Asociación para la Investigación de Medios de Comunicación) del primer cuatrimestre de 2020, y escogimos los periódicos de mayor tirada y difusión en España según la fuente citada (Figura 1).

Así, de los datos del gráfico, los tres periódicos nacionales de información general con más lectores son El País, El Mundo y $A B C$. En este estudio, no se han incluido La Voz de Galicia ni La Vanguardia por su carácter local, aun cuando La Vanguardia, de las trece ediciones, cuatro corresponden a otras comunidades autónomas aparte de Cataluña (Comunidad Valenciana, País Vasco, Andalucía y Madrid).

En un primer momento, nos planteamos realizar un análisis de la prensa y contrastarla con los medios oficiales de la presidencia del Gobierno; sin embargo, a medida que avanzaba la investigación, se desestimó, ya que, aunque los medios oficiales, en especial en la cadena estatal 24 Horas, se trató el tema, la muestra no era lo suficientemente significativa. En la web oficial habilitada, dedicaron una sección a educación y formación profesional, pero el número de noticias fue muy escaso: 8 en junio, 9 en mayo, 4 en abril y 9 en marzo, y muy pocas de ellas hacían referencia a la educación superior (Presidencia del Gobierno, 2020).

Analizamos también la web que el Ministerio de Universidades comparte con el Ministerio de Ciencia e Innovación, y nos detenemos en el apartado de información que habilitaron sobre «Universidades y covid-19» (Ministerio de Ciencia e Innovación, 2020). En esta sección, se informa sobre las diferentes actuaciones $v$ procedimientos de este ministerio; esto es, ho-

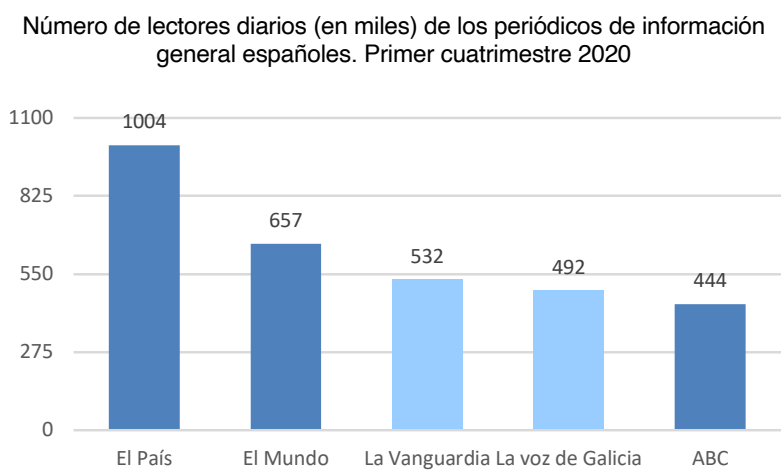

Figura 1. Lectores diarios de los periódicos de información general españoles. Fuente: Elaboración propia a partir de AIMC (Asociación para la Investigación de Medios de Comunicación, 2020). 
mologaciones, legalizaciones, registro, credenciales, etc., por lo que no lo incluimos, ya que no aportaban resultados significativos para los objetivos de nuestra investigación.

Finalmente, en Google Noticias realizamos un filtrado de artículos con las variables «Universidad/educación superior» y «Covid». Los resultados obtenidos fueron 346 noticias en diferentes medios. Sin embargo, observamos que solo treinta, menos del 10\%, correspondían a las principales cabeceras nacionales (El País, El Mundo y $A B C$ ). A su vez, de esas treinta, solo once se encontraban dentro de la sección de educación, o al menos etiquetadas como tal en los diarios referidos. Posiblemente, las restricciones impuestas por la legislación española a los buscadores, motivo por el cual ha cerrado Google Noticias en España (Google, 2020), impidieron una correcta métrica. Por otra parte, tal vez resulte interesante para estudios posteriores hacer una lectura más a fondo de las fuentes de información a las que accede la población en general a la hora de informarse. Por todo ello, los resultados no se tomaron en cuenta para el presente estudio.

\subsection{TAMAÑo Y FECHA DE LA MUESTRA}

En la muestra, utilizamos el cien por cien de las informaciones aparecidas en las secciones de educación de los periódicos seleccionados. Además, incluimos todas aquellas noticias que, fuera de estas secciones, respondían a la búsqueda de «covid/pandemia/estado de alarma + universidad/estudios superiores". En el caso de El País, esta búsqueda fue solo hasta el 30 de mayo, pues al día siguiente abrió una nueva sección «El País Educación», donde se agrupan todas las noticias sobre el tema: agenda política, reformas, nuevos grados universitarios, tribunas y secciones que dan cabida a las opiniones de docentes y expertos junto con una comunicación semanal a sus suscriptores con los temas más destacados (El País, 2020).

El total de informaciones recopiladas dedicadas al tema de la educación en el estado de alarma fue de 3467 . De estas, en un primer filtrado a través del análisis del título y la entradiIla, seleccionamos 1059, ya que muchos artículos, aun estando en la sección de educación, hablaban de la etapa escolar previa a los estudios superiores. Este millar de noticias fue visto a través de web y quedaron como relevantes 865 artículos (Figura 2).

Cantidad de noticias desde el total inicial hasta la selección final

Total informaciones extraidas (incluyendo Google)

3813

Total informaciones de los tres diarios seleccionados 3467

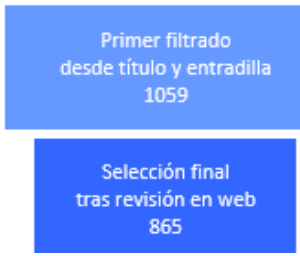

Figura 2. Selección de noticias. Fuente: Elaboración propia. 
El período de fechas de la muestra fue de tres meses y veinte días, desde el 10 de marzo hasta el 1 de julio de 2020. Si bien el estado de alarma se inició el 14 de marzo de 2020 y se levantó el 21 de junio (00:00 h), en la recogida de la muestra hemos incluido unos días por delante, pues ya los propios medios reflejaban una cierta inquietud por el elevado número de contagios, y otros días tras su finalización, ya que la situación de algunas comunidades autónomas todavía era similar al último período del estado de alarma.

\section{Discusión}

Para la presentación de los resultados, seguiremos el mismo orden propuesto en los objetivos: 1) temas presentes en los principales periódicos cuando abordan el tema de la educación superior; 2) docencia; 3) investigación; 4) relación Gobierno y Universidad, y 5) intervención de la Universidad en los medios.

\subsection{Temas}

En el siguiente gráfico, se muestran los temas de mayor interés para los tres periódicos digitales que hemos estudiado (Figura 3).

Si analizamos el gráfico, claramente se observa que la docencia, la investigación y la opinión de los académicos y rectores han sido los tres temas prioritarios para los medios. También se puede señalar que la actuación del Gobierno, aunque con un porcentaje inferior, ha tenido interés mediático. Hemos dejado en un bloque aparte los artículos referentes a la EvAU (evaluación para el acceso a la universidad) por su especificidad.

Respecto a los temas cruzados con la variable «Fecha», no hallamos conclusiones relevantes, salvo algunos picos de temas coincidentes: al inicio de la pandemia, la atención se centraba en el cierre de las universidades y el inicio de las clases online, y finalizando el estado de alarma se habla de las pruebas de la selectividad, sobre todo durante los meses de abril v iunio.

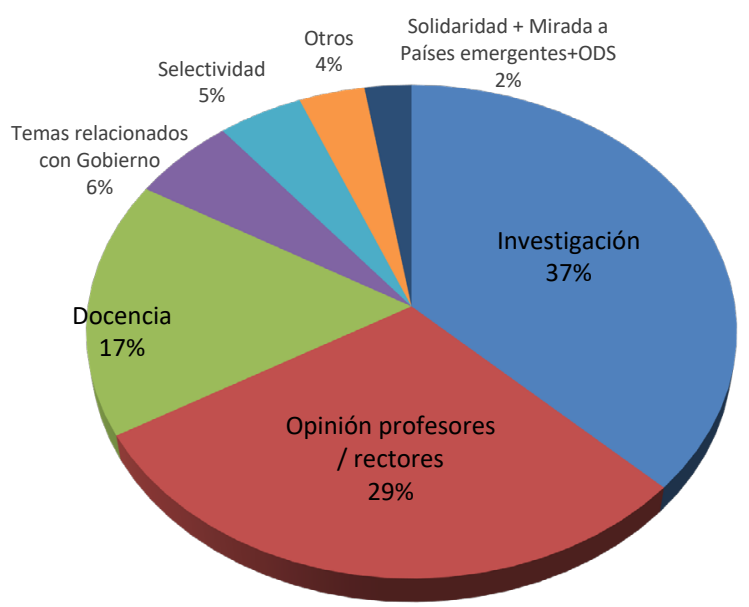

Figura 3. Distribución de temas abordados en la prensa digital. Fuente: Elaboración propia. 
Otro tema que, conforme avanza el tiempo, merece un mayor interés mediático es el de la investigación, en especial cuando se relaciona con la posibilidad de realizar algún descubrimiento importante de vacuna o fármacos.

\subsection{DOCENCIA}

Descritas las áreas temáticas, vamos a entrar en el análisis de estas y extraer aquellas nociones que más presencia tienen, las cuales vemos en el siguiente gráfico (Figura 4).

Dentro de «Docencia», apreciamos que la situación de no presencialidad ha obligado a un modo nuevo: la enseñanza en remoto, y con ella a multitud de transformaciones en las estructuras de las instituciones y, en especial, a la adaptación de este nuevo modelo para el profesorado y alumnado.

Si extraemos otra tabla cruzando variables, descubrimos que seis de cada diez artículos englobados en «Docencia» hacían referencia al tema digital.

\subsubsection{La enseñanza digital. ¿Cambio de paradigma?}

Llama la atención la cantidad de columnistas y artículos de opinión con un tono reflexivo y crítico. La tecnología es analizada desde su aspecto positivo como aliada necesaria para hacer frente a la no presencialidad, pero a su vez descubrimos que la prensa constantemente denuncia la falta de medios, la poca formación por parte del profesorado para adaptarse a esta nueva situación, la brecha entre unos estudiantes y otros, y la coherencia del modo de evaluación con los resultados de aprendizaje buscados. Mientras que la sociedad ha dado pasos de gigante en la incorporación de nuevas maneras de comunicarse, compartir documentos y trabajo en modo colaborativo, la docencia universitaria apenas ha pasado de la tiza a los cañones de proyección.

A la par, hay una mirada crítica hacia el online o enseñanza en remoto, lo que reafirma la riqueza insustituible de la enseñanza presencial y desvela un nuevo modo de interpretar el proceso de enseñanza-aprendizaje y, en el fondo, de volver a las raíces de la Universidad, donde el estudiante es piedra angular. Hay un reclamo de mayor dedicación en comunidad. esto es. incrementar no solo formación $v$ tecnoloaía. sino sineraias entre profesores $v$

Distribución subtemas dentro del área temática «Docecia»

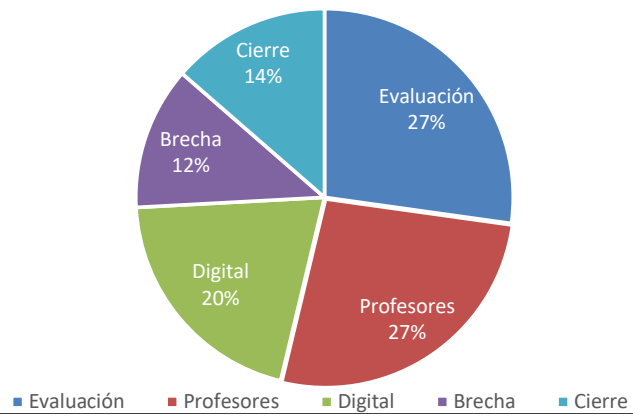

Figura 4. Distribución de subtemas dentro del área temática «Docencia». Fuente: Elaboración propia. 
asignaturas, potenciar el acompañamiento de los estudiantes y el trabajo entre ellos, y forjar nuevos procesos de comunicación y evaluación (Goñi, 2020). Por otra parte, se ve necesario conjugar las necesidades de la Universidad con las demandas del mercado e incorporar la formación de profesores y estudiantes en un entorno de aprendizaje que facilite el uso e interpretación de los datos (Munguia et al., 2020).

Entre los artículos analizados, encontramos las dos miradas que están presentes también en el ámbito educativo: por un lado, hay un cambio propiciado por la situación vivida tras el estado de alarma, que nos hace entrar en una era digital para abordar los retos que nos depara la educación del futuro; por otro lado, hay un cierto temor a que la docencia universitaria pierda la presencialidad y el contacto directo con el estudiante, y entremos en un mundo meramente virtual. Se reclama una formación integral; esto es, que mire a la persona en su totalidad. La forma espacial no es menor. El gesto, la mirada, el lenguaje no verbal son difícilmente sustituidos por una pantalla. Es imprescindible recuperar el roce humano, las experiencias vitales compartidas, el espacio común de convivencia y «alcanzar una razonada proporción entre virtualidad y contacto humano. Pero sin olvidar que la columna vertebral de la formación reside en este último» (Campos, 2020).

Finalmente, hay que destacar la importancia del papel de la prensa como despertador crítico y acicate para aquellos que tienen la responsabilidad de gobernar y ordenar prioridades. La entradilla del artículo de El País del periodista Pablo Simón es muy significativa: «Si un país tiene antes un plan para ordenar sus playas y terrazas que su sistema educativo algo no va demasiado bien» (2020).

\subsubsection{Brecha digital}

Ciertamente, la epidemia ha destapado la brecha digital y ha puesto de relieve el muro que se establece para aquellos estudiantes que no pueden acceder a internet, bien por no poseer los equipos necesarios, bien por no tener una banda ancha adecuada (Daniele, 2020).

En el siguiente gráfico, elaborado con los datos suministrados por el INE (Instituto Nacional de Estadística) en su Encuesta sobre equipamiento y uso de tecnologías de información y comunicación en los hogares 2019, apreciamos la diferencia entre los hogares del primer cuartil económico y el último (Figura 5).

\% Equipamiento TIC Hogares 2019

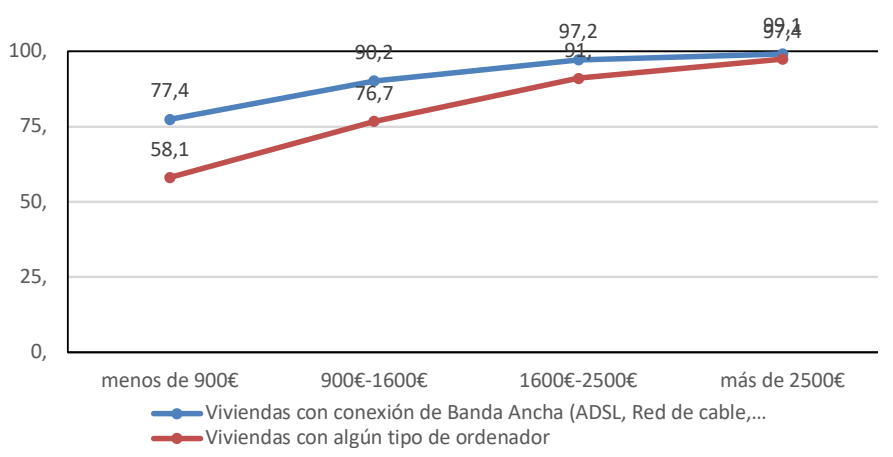

Figura 5. Porcentaje de equipamiento en los hogares de España en 2019. Fuente: Elaboración propia a partir de INE, 2020. 
Uno de cada cuatro hogares con rentas entre 900 y $1600 €$ no tiene ordenador, ni tampoco uno de cada diez en el siguiente cuartil con rentas entre 1600 y $2500 €$.

El tema se agrava, pues en la enseñanza universitaria las clases en línea han sido práctica común. El informe de la Conferencia de Rectores de las Universidades Españolas (CRUE) estima que el $3 \%$ del alumnado (36 000) tiene problemas técnicos para seguir las clases (Silió, 2020b). En un estudio mencionado por El País, se dice que «las siete universidades públicas han detectado al menos 615 estudiantes sin recursos tecnológicos adecuados para seguir las clases» (Vallespín, 2020). En esta línea, el rector de la Universidad de A Coruña, Julio Abalde, manifestó lo que sigue: «A 3000 de mis estudiantes les está fallando la conectividad», lo cual supone un $20 \%$ de los alumnos.

A pesar de la gravedad que encierran estas afirmaciones, en los artículos hallados durante el período de alarma apenas se hace referencia a esta realidad (un $12 \%$ dentro del área temática «Docencia» y casi un $2 \%$ en el conjunto total encontrado).

Algunas noticias sobre este tema tuvieron un impacto alto de lectura en el día de su publicación, pero sin continuidad en el tiempo. Un claro ejemplo fue la huelga telemática convocada por el sindicato estudiantil Anega el 16 de abril ante la discriminación frente a los jóvenes que no pueden tener acceso a las clases de forma remota (Vizoso, 2020).

\subsubsection{Evaluación}

La evaluación ha sido una preocupación continua en la educación. En el contexto de la no presencialidad y la obligación de hacer exámenes en remoto, se ha puesto en tela de juicio el fundamento de la propia evaluación y su alcance. Sin embargo, este fondo de la cuestión no ha tenido apenas resonancia en los artículos estudiados. Un gran porcentaje de estos se han concentrado en cuestiones de forma, en especial sobre los diferentes métodos para asegurar que no hubiese fraude ni plagio.

Sin embargo, un $12 \%$ de los artículos, generalmente de opinión, han puesto sobre la palestra pública el objeto y función del proceso evaluador, que tiene que ir más allá del momento puntual de un examen y que reclama un conjunto de hitos a lo largo del año, como la evaluación continua.

Finalmente, varias de estas informaciones salen al paso frente a las voces que reclamaban un aprobado general manifestando que tal cuestión generaría efectos perniciosos en especial sobre los estudiantes -en palabras de Antonio López, rector de la Universidad de Santiago de Compostela (Gómez, 2020) - . Un estudio realizado por la Universidad de Granada sobre la opinión de 3047 profesores muestra el rechazo de estos frente a un aprobado general, al estimar que no sería justo ni reforzaría el valor del esfuerzo y el mérito (Menárguez, 2020a).

En esta línea, la CRUE elaboró el extenso y completo Informe sobre procedimientos de evaluación no presencial. Estudio del impacto de su implantación en las universidades españolas y recomendaciones (2020c).

Hubiera sido deseable que se publicaran más artículos de fondo donde se planteara la necesidad de incorporar la evaluación como análisis y retroalimentación del proceso formativo, y se descubriesen las áreas de mejora sobre las que seguir trabajando (Hattie y Timperley, 
2020). No se trata de transmitir una información que los estudiantes pueden procesar y repetir de manera impecable, sino de establecer el camino donde el alumno es protagonista activo de su aprendizaje y este se torna realmente significativo (Resnick, 2002).

\subsubsection{El profesorado}

Hemos considerado interesante hacer un breve apunte sobre el profesorado y su presencia en los medios. Un $68 \%$ de los artículos con referencias al profesorado plantean problemas concretos de contratación (prórrogas de los contratos temporales durante el estado de alarma, falta de formación o medios, etc.). Un $24 \%$ toca temas irrelevantes o noticias del momento o solo de ámbito local. Hay, sin embargo, un pequeño porcentaje (8\%), generalmente de opinión, que denuncia la invisibilidad del profesorado y reclama una mayor valoración de su vocación docente, expresada en los múltiples esfuerzos realizados para continuar con la docencia, su capacidad autodidacta y de acelerada adaptación en medio de un contexto hostil y de mucho miedo, el incremento de horas de trabajo y de tutorías individualizadas con los estudiantes, etc.

\subsection{INVESTIGACIÓN}

La investigación es una de las grandes áreas temáticas, con un 37\% de presencia sobre el total de los artículos. Al igual que en el anterior epígrafe, observemos la distribución de los subtemas tratados (Figura 6).

Prácticamente, nueve de cada diez artículos hacían referencia a aspectos relacionados con el virus o la enfermedad: avances y descubrimientos en el conocimiento del SARS-CoV-2, etiología, síntomas en los contagiados (respiratorios, gastrointestinales, etc.), proceso, afectación diversa en la población, grupos de riesgo, fármacos, primeros pasos en la vacuna, etc. En este aspecto, hay una coincidencia con las métricas devueltas por los buscadores de noticias de Google, donde el $42 \%$ informaba sobre temas relacionados con el virus o la enfermedad.

Otro dato para destacar es que la mayoría de los artículos contenían apreciaciones directamente expresadas por las universidades que estaban detrás de esas investigaciones. La lista de universidades mencionadas por los medios es extensa. Oxford - a la cabeza-

Distribución temática dentro de Investigación

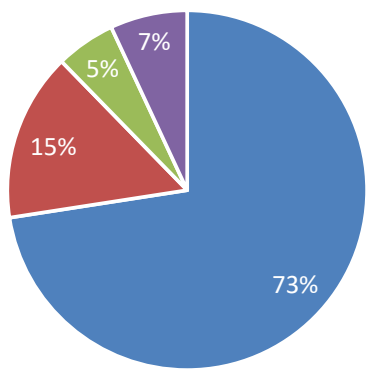

- Investigación universidades (datos de las mismas Universidades)

- Datos elaborados por redacción diario sobre Investig vacuna + farmacos

- Investigación en Matemática/Estadística con aplicacion a predicciones (muertes, economía...)

- Invest NO COVID

Figura 6. Distribución de subtemas dentro del área temática «Investigación». Fuente: Elaboración propia. 
y también muchas de Estados Unidos: Tennessee, Pittsburg, Maryland, lowa, Georgia, Washington, Nueva York, etc. La presencia de las universidades españolas ha sido casi nula, y muy pocas universidades han aparecido más de dos veces en los medios principales.

Ha habido también un aporte de otras áreas de investigación de las universidades, como ingeniería, matemáticas y economía. Se han tornado especialmente relevantes los estudios de matemáticas y estadística para la predicción de las curvas de contagiados y muertos y los tiempos de duración. También las investigaciones económicas han tenido un papel importante que ha ido creciendo conforme se alargaba el estado de alarma.

Una sombra del análisis de los temas abordados dentro de investigación es la escasa presencia de investigaciones ajenas a la covid-19. Solo un $7 \%$ de los artículos durante estos meses han publicado otro tipo de investigaciones. Algunos de los temas han sido petróleo, astronomía, animales en peligro de extinción, reciclaje y sostenibilidad, calidad del aire, etc.

\subsection{Relación Gobierno y Universidad}

Los artículos con referencias al Gobierno de España o a Gobiernos autonómicos han supuesto el $6 \%$ del total de los artículos seleccionados como relevantes. Los temas tratados podríamos agruparlos en tres grandes bloques:

1. Cuestiones administrativas relacionadas con la universidad, en especial la pública: contratos de profesorado y personal investigador, aplazamiento de oposiciones, tasas académicas, precios de las carreras y becas universitarias, reglamentos disciplinarios, intervenciones del ministro Manuel Castells, intervenciones de los Gobiernos autonómicos para paliar la brecha digital, regular cuestiones económicas, etc.

2. Cuestiones relacionadas con la docencia: cierre de aulas, modos de evaluación y realización de exámenes y protocolos de vuelta a la universidad.

3. Relación Gobierno-Universidad para fortalecer el seguimiento de la crisis, las decisiones de salud y seguridad de la ciudadanía, contención de la progresión de la enfermedad y los refuerzos en el sistema de salud pública.

El porcentaje de presencia de estos ha sido el que aparece en la figura 7.

Distribución temáticas relación Gobierno-Universidad

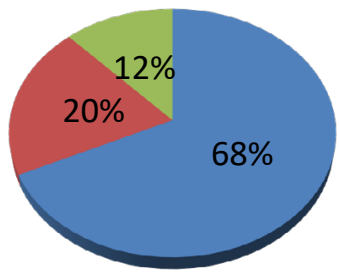

- Cuestiones administrativas

- Docencia

- Relación Gobierno Universidad para seguimiento/ decisiones ante la crisis

Figura 7. Distribución de subtemas dentro del área temática «Relación Gobierno-Universidad». Fuente: Elaboración propia. 
Con abrumadora diferencia, los temas más destacados por los medios en relación con el Gobierno son los administrativos. Solo este dato nos plantea en qué lugar en el índice de prioridades quedan la investigación y la docencia. Por otra parte, es propio de aquellos que gobiernan que su injerencia sea en aquellos temas propios del Gobierno, como los administrativos, pero es significativo poner de manifiesto que los temas de relevancia para el ámbito académico deberían haberse tratado con más seriedad y profundidad.

La importancia del papel que ejercen los medios de comunicación para informar, formar y ayudar a desgranar los temas complejos, como los económicos, es indudable. No podemos olvidar que los medios de comunicación ayudan a generar debate y opinión sobre aspectos de vital importancia para la población, a la vez que ponen de manifiesto las grandes injusticias y desigualdades.

Nos detenemos en el análisis de algunos elementos del primer y último bloque: las tasas y las becas, y el papel de la investigación apoyado desde las universidades. Dejamos sin comentario el bloque referente a la docencia, pues ya lo hemos analizado antes en este estudio.

\subsubsection{Tasas y becas}

Dos temas de las cuestiones administrativas que afectan directamente al alumnado, y por ende con gran repercusión en medios, han sido tasas y becas.

Así, los temas más tratados han sido la derogación por parte del Gobierno de las horquillas en los precios de la matrícula en las universidades públicas a inicios de mayo $(A B C$, 2020a) y, a la par, la ausencia de una contrapartida económica que sostenga tal decisión (Sanmartín, 2020; Silió y Vallespín, 2020). Este es un claro ejemplo del influjo de los periódicos en la vida política y su papel no solo de descriptores de la realidad, sino de analistas que ponen en juego diversos pareceres (en este último ejemplo, entre Gobierno central y Gobiernos autonómicos) y que reclaman acciones reales y posibles. Su labor no es solo informativa, sino de alguna manera performativa.

Respecto a las becas, los artículos de prensa encontrados han despertado el fondo de la polémica: cuáles deberían ser los requisitos para obtener una beca, o si solo basta tener una renta baja y apenas un aprobado. Se han puesto en cuestión los beneficios de exigir menos académicamente y si ello es provocador de motivación o más bien de lo contrario, de desmotivación de los más vulnerables (Menárguez, 2020b). Por otra parte, parece lógico que las ayudas para la educación sean para aquellos que realmente las aprovechan con su estudio y sus resultados. Rebajar la nota no responde a una cuestión de justicia social, sino a un modelo que iguala por lo bajo y deja de lado el sacrificio y la generación de valor añadido ( $A B C, 2020 \mathrm{~b})$.

\subsubsection{Investigación y apoyo de las universidades}

En la prensa, apenas se ha explicitado la queja de investigadores de otras áreas que han visto cerrados sus laboratorios y detenidas sus investigaciones, pues no eran de un sector habilitado para trabajar. Los científicos que precisaban viajar o desplazarse para realizar trabajos de campo, los que investigaban con organismos vivos, etc., han debido interrumpir sus trabajos. De estos últimos, muchos han tenido dificultades para mantener los laboratorios o 
animalarios en condiciones, y muchos de los estudios que dependían de las condiciones del organismo (por su etapa vital, floración, avance del tumor o de la enfermedad inoculada, etc.) han tenido que ser anulados, lo que ha supuesto un retraso importante, pues no en todos los casos se pueden retomar donde se dejaron. Aunque ha habido alguna noticia en la prensa, han sido fundamentalmente las agencias o medios especializados los que han denunciado el error de no considerar esencial la investigación (Marcos, 2020; Segura, 2020).

Con algo más de presencia en la prensa de cabecera ( $4 \%$ del total de artículos de esta área) ha estado la situación congelada de los laboratorios de las universidades con capacidad de realización de pruebas PCR (Montañés, 2020; Piña, 2020).

Al día siguiente del llamamiento realizado por el Gobierno de España de apoyo de las universidades, la CRUE puso a disposición 1837 expertos en detección de la covid-19 y más de trescientos laboratorios, así como una importante cantidad equipos de protección, material fungible, etc. (CRUE, 2020b).

Especialmente en el inicio, diversas entidades comunicaron «cierta tensión entre la información aportada e interpretada por los científicos expertos y las decisiones políticas tomadas a continuación por las autoridades» (CRUE et al., 2020). En el análisis de prensa realizado, han sido muy escasas las informaciones sobre esta iniciativa, aun cuando muchas entidades se han adherido al Manifiesto por la ciencia que se realizó para denunciar estos hechos.

\subsection{Intervención de la Universidad en los medios}

En los diarios, hay una gran participación de personal académico gestando opinión. Tal como vemos en el gráfico, casi uno de cada tres artículos revisados tenía una intervención de un profesor o de algún miembro de la dirección, fundamentalmente rectores. Esta primera aproximación desde el dato cuantitativo al menos nos indica que en la redacción de las informaciones sí se ha contado de manera especial con la opinión de aquellos que conocían de cerca el tema sobre el que se estaba informando (Figura 8).

Respecto a los asuntos tratados, el profesorado ha abordado una infinidad de temas, prácticamente todos los analizados en este estudio. Sus intervenciones han sido fundamentalmente para explicar conceptos desde las áreas de saber en las que ellos eran expertos. El

Porcentaje de artículos con opinión de rectores o profesores

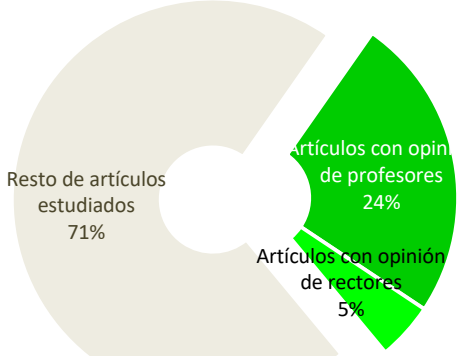

Figura 8. Porcentaje de artículos con opinión de rectores o profesores. Fuente: Elaboración propia. 
abanico de saberes cubiertos es muy grande, aunque destacan los relacionados con estudios científicos próximos al virus y, en menor grado, pero también relevantes, estudios matemáti$\cos$ (predicciones y curvas de contagios y muertes) y expertos de las ciencias jurídico-empresariales (derecho, economía, etc.).

Por tanto, cabe señalar como dato significativo la representación de las universidades en todos los medios de comunicación. Prácticamente todas, en algún momento, han intervenido con sus aportaciones en artículos de prensa. Como nota curiosa, nos ha sorprendido que el periódico que más ha acudido a la cita textual de profesores o rectores haya sido $A B C$, con una ratio de diferencia sobre los otros de casi 4:1.

Los rectores han estado muy unidos en el refuerzo de comunicados ya expresados a través de sus entidades o de las instituciones que los representan, especialmente la CRUE. Los temas abordados han dado juego a los diarios, pues generalmente aportaban elementos críticos o al menos importantes para la reflexión sobre las decisiones tomadas por parte de las entidades gubernamentales. El 14 de marzo, la CRUE emitía un comunicado, por la declaración del estado de alarma, en el que trasladaba un mensaje de tranquilidad a toda la sociedad española y anunciaba la creación de un grupo de trabajo para abordar las medidas estatales que se iban a establecer para la optimización de las herramientas y procedimientos de docencia no presencial (CRUE, 2020a).

Casi un mes después, el 13 de abril, la CRUE, junto con las instituciones científicas COSCE (Confederación de Sociedades Científicas de España), FACME (Federación de Asociaciones Científico Médicas Españolas) y SOMMa (Alianza de Centros Severo Ochoa y Unidades María de Maeztu), vuelve a señalar las divergencias generadas, especialmente al inicio de la propagación de la pandemia, entre la información aportada e interpretada por los científicos y las decisiones políticas tomadas por las autoridades. En este comunicado, se habla de una falta de sintonía que ha podido perjudicar la idoneidad de las medidas adoptadas y se explicitan las medidas para que estos desencuentros no dificulten la batalla contra la pandemia. Así, se aconseja, entre otras cosas, por una parte, activar un sistema de información adecuado a las nuevas expectativas de flexibilidad e inmediatez que demanda la información científica y, por otra, desplegar una red de asesoramiento científico a los poderes ejecutivo, legislativo y judicial, transparente e independiente, que debería estar cubriendo todos los niveles de la Administración (CRUE et al., 2020).

\section{Conclusiones}

Nuestros objetivos eran profundizar sobre el tratamiento informativo de la educación superior durante el estado de alarma en la prensa digital española; señalar los temas de mayor interés para los principales periódicos; analizar su tratamiento en los medios, y señalar la cabida que han dado los medios a las opiniones de los académicos y rectores.

La prensa no ha permanecido indiferente a lo que ha significado para la universidad la pandemia. El problema reside en establecer qué cuestiones se han denunciado y cuáles han pasado inadvertidas.

Realizado el análisis que nos planteamos como primer objetivo, se ha hecho evidente que la docencia, la investigación y la opinión de los académicos y rectores han sido los tres temas 
prioritarios para los medios, seguidos, aunque con un porcentaje inferior, por las relaciones entre el Gobierno y la Universidad. Intereses que se han mantenido constantes a lo largo del período estudiado. El factor tiempo solo ha afectado a algunos temas menores: al inicio de la pandemia la atención se centró en el desalojo de las universidades y el inicio de la enseñanza online y, finalizando el estado de alarma, cobró más importancia la EvAU.

La Universidad, ante la implantación forzosa y generalizada de una enseñanza en remoto, no ha podido ignorar la llamada brecha digital, el problema de la evaluación ni, muy especialmente, el cambio de paradigma docente. ¿Qué podemos concluir sobre el reflejo de estas cuestiones en la prensa?

La escasa presencia de la brecha digital en los artículos rastreados pone de manifiesto, para sorpresa de muchos, que no es un problema que afecta únicamente a los sectores inferiores del sistema educativo. Las autoridades académicas lo han denunciado, y no cabe ignorarlo si la prolongación de la pandemia o la confianza en los nuevos métodos docentes va a primar la enseñanza en remoto.

Del mismo modo, la prensa no ha permanecido ajena a las dificultades asociadas a las nuevas formas de enseñanza, a la división del mundo universitario entre los reticentes ante la innovación y los entusiastas defensores de esta. División que, a su vez, se ha reflejado en la imagen de los procesos evaluativos que se han debido implantar. Lo que ha ocupado a la prensa, manifestación de lo que preocupaba a la mayoría de la sociedad, ha sido cómo iban a ser los exámenes, y no tanto cuál ha de ser el sentido educativo de la evaluación. La Universidad se ha planteado todo esto. Creemos que no ha hecho más que empezar a hacerlo y, por lo mismo, la presencia de estos problemas en la prensa ha sido muy superficial.

Como no podía ser menos, la investigación se ha hecho muy presente en las noticias sobre la Universidad. Lo más llamativo es la presencia casi exclusiva de las noticias relacionadas con la investigación en torno a la covid-19, que la prensa -también en la mayoría de los casos - reflejara apreciaciones directamente expresadas por las universidades y que las noticias fueran replicadas casi de manera idéntica por los diferentes medios. Al mismo tiempo, rara ha sido la información centrada en investigaciones ajenas a la covid-19. Esta presencia dice mucho sobre nuestro sistema universitario. La urgencia ha hecho que, durante meses, prácticamente todo haya sido covid. Se ha reconocido el servicio prestado por las universidades en la lucha contra la pandemia y se han denunciado errores. La prensa ha reflejado el error de no considerar esencial la investigación, de no considerarla esencial durante años y de no considerarla esencial en estos momentos si no trataba directamente de la covid-19.

Los temas más destacados por los medios en relación con el Gobierno son los administrativos. Este dato ya plantea en qué lugar en el índice de prioridades quedan la investigación y la docencia; los temas de relevancia para el ámbito académico deberían haberse tratado con más seriedad y profundidad.

En relación con las tasas y las becas, el análisis de la prensa ha manifestado claramente tanto la dificultad del problema - por ejemplo, cómo compaginar la derogación por parte del Gobierno de las horquillas en los precios de la matrícula en las universidades públicas con la ausencia de una contrapartida económica que sostenga tal decisión o sobre qué bases establecer los requisitos para la concesión de becas - como el debate político que contiene.

Los datos cuantitativos indican que, en la redacción de la información, se ha contado con la opinión de los universitarios, pero su intervención ha sido fundamentalmente para explicar 
conceptos desde las áreas de saber en las que ellos eran expertos. Del mismo modo, la activa presencia de los rectores en la prensa, a través de la CRUE, no ha introducido temas significativamente diferentes a los ya señalados, a excepción de la capital insistencia en las graves y perjudiciales divergencias entre la información aportada e interpretada por los científicos y las decisiones políticas tomadas por las autoridades.

Los medios de comunicación desarrollan una función esencial: vigilan y fiscalizan a los que tienen la responsabilidad de gobernar y, al tiempo, informan, forman y ayudan a desgranar los temas complejos; es decir, ayudan a generar debate y opinión sobre asuntos socialmente capitales. Todo esto es evidente, pero su éxito depende de su receptividad ante las instituciones y de la capacidad de estas de hacerse visibles.

En definitiva, teniendo en cuenta los objetivos planteados, el análisis nos obliga a reflexionar, a construir una prospectiva teórica sobre el futuro de la Universidad como institución de servicio en una sociedad democrática. La prensa denuncia, plantea la situación social, pero la profundidad de la reflexión debe hacerse en el seno de la Universidad. Una institución que tiene, hoy por hoy, un problema radical de identidad debido a la heterogeneidad de realidades formativas que acoge y cuya viabilidad futura depende del reconocimiento -explícito y, por lo tanto, transformador - de esta realidad: no podemos seguir afirmando que todos los estudiantes, las carreras, los futuros y las responsabilidades son iguales; ni afirmarlo ni comportarnos como si esto fuese así. Quizá las nuevas tecnologías ayuden a hacer convivir itinerarios y expectativas diversas.

La reflexión debe realizarse, y trasladarse a la opinión pública sin renunciar a las tres dimensiones de la Universidad: la formativa, la investigadora y, en consecuencia, la de servicio. La universidad debe hacerse presente como una institución formativa para el conjunto de la sociedad, cuyo prestigio se vincula a una cualificación, un ideal de servicio y una independencia política. El estallido de la pandemia ha sometido a todo el sistema a un triple proceso. Tras la interrupción inicial, que paralizó el sistema, y la adaptación, que forzó una respuesta rápida, en gran medida contraria a una institución cuyo ritmo de actuación es lento por definición, llega el momento de la normalización: asumir las ventajas de la digitalización, reivindicar la condición de expertos frente a una sociedad donde predomina la emoción e insistir, como fundamento del ser universitario y de la viabilidad de una sociedad democrática, en la prioridad de los deberes sobre los derechos.

\section{Bibliografía}

ABC (5 de mayo de 2020a). El Gobierno deroga el sistema de horquillas en el cobro de las tasas universitarias. $A B C$. https://www.abc.es/sociedad/abci-gobierno-deroga-sistema-horquillas-cobrotasas-universitarias-202005051558_noticia.html

ABC (24 de mayo de 2020b). El igualitarismo rechaza el esfuerzo. ABC. https://www.abc.es/opinion/ abci-abc-igualitarismo-rechaza-esfuerzo-202005242307_noticia.html

AIMC (2020). Ranking de Diarios 2020-1. ${ }^{a}$ ola. http://reporting.aimc.es/index.html\#/main/diarios

Barroso, J. (2000). Los medios de comunicación como creadores de imagen social. La imagen de la universidad en la prensa. Revista Enseñanza Universitaria, 16, 39-55.

Beetham, H. (Ed.) (2013). Rethinking pedagogy for a digital age: Designing for 21st century learning. Routledge. 
Bucknell, B. (2016). The innovative University: Changing the DNA of higher education from the inside out by Clayton M. Christensen and Henry J. Eyring (review). ESC: English Studies in Canada, 42(1), 217-231. https://doi.org/10.1353/esc.2016.0000

Caminos, J. M., Marín, F. y Armentia, J. I. (2008). Novedades en el diseño de la prensa digital española (2000-2008). Palabra Clave, 11(2), 253-269.

Campos, P. (29 de abril de 2020). Formación onliney deshumanización: Los riesgos del post-Covid-19. ABC. https://www.abc.es/familia/educacion/abci-formacion-online-y-deshumanizacion-riesgos-postcovid-19-202004300121_noticia.html

Comunian, R., Gilmore, A. y Jacobi, S. (2015). Higher education and the creative economy: Creative Graduates, knowledge transfer and regional impact debates. Geography Compass, 9(7), 371-383. https://doi.org/10.1111/gec3.12220

CRUE (2020a). Comunicado por la declaración del estado de alarma a consecuencia de la pandemia del Covid-19. http://www.crue.org/Documentos\%20compartidos/Comunicados/2020.03.14Comunicado\%20estado\%20alarma.pdf

CRUE (19 de marzo de 2020b). Comunicación-Disposición expertos y donación material fungible Covid-19. http://www.crue.org/Comunicacion/Noticias/donaci\%C3\%B3n\%20material\%20fungible\%20covid.aspx

CRUE (2020c). Informe procedimientos evaluación no presencial. http://www.crue.org/

Documentos\%20compartidos/Informes\%20y\%20Posicionamientos/Informe\%20procedimientos\% 20evaluacio\%CC\%81n\%20no\%20presencial.pdf

CRUE, FACME, SOMMa y COSCE (2020). Comunicado sobre el cometido de la ciencia en la resolución de la crisis generada por la pandemia de coronavirus SARS-CoV-2. http://www.crue.org/ Documentos\%20compartidos/Comunicados/COSCE.\%20\%20Comunicado\%20sobre\%20el\%20 cometido\%20de\%20la\%20ciencia\%20en\%20crisis\%20de\%20la\%20Covid-19ff.pdf

Daniele, L. (31 de mayo de 2020). La epidemia destapa la brecha digital y pone contra las cuerdas a un millón de alumnos. $A B C$. https://www.abc.es/sociedad/abci-epidemia-destapa-brecha-digital-ypone-entre-cuerdas-millon-alumnos-202006010133_noticia.html

De la Torre, E. M., Agasisti, T. y Pérez-Esparrells, C. (2017). The relevance of knowledge transfer for universities' efficiency scores: An empirical approximation on the Spanish public higher education system. Research Evaluation, 26(3), 211-229. https://doi.org/10.1093/reseval/rvx022

El País (2020, mayo 30). El País refuerza sus contenidos sobre educación y lanza una nueva sección. El País. https://elpais.com/sociedad/2020-05-30/el-pais-refuerza-sus-contenidos-sobre-educacion-ylanza-una-nueva-seccion.html

Etzkowitz, H. (2018). The triple helix: University-industry-government innovation and entrepreneurship. Routledge.

Fernández, S. y Molero, L. (2003). Construcción lingüística de la imagen de la Universidad del Zulia en Panorama. Opción, 19(41), 58-84.

García, F. J. (2011). La Universidad de la próxima década: La Universidad digital. En Universidad y desarrollo social de la web (pp. 181-197). Editandum. https://www.researchgate.net/publication/ 236620683_La_Universidad_de_la_proxima_decada_La_Universidad_Digital

García, J.-A. (1993). Medios de comunicación y universidad. Revista Comunicar, 1(1), 66-74. https://doi. org/10.3916/C01-1993-08

Gómez, D. (13 de abril de 2020). El rector de la USC: «Suspender el curso sin evaluar tendría efectos muy perniciosos». $A B C$. https://www.abc.es/espana/galicia/abci-coronavirus-galicia-rectorsuspender-curso-sin-evaluar-tendria-efectos-perniciosos-202004131011_noticia.html 
Goñi, J. G. (16 de abril de 2020). Un punto de inflexión para las universidades públicas españolas. El País. https://elpais.com/elpais/2020/04/16/opinion/1587049727_620802.html

Google (2020). Comunicado cierre Google Noticias en España. Centro de Editores de Google. https:// support.google.com/news/publisher-center/answer/9609687?hl=es

Hattie, J. y Timperley, H. (2020). The power of feedback. Review of Educational Research, 77, 81-112. https://doi.org/10.3102/00346543029848

Herranz, J. M., Tapia, A. y Vicente, A. (2009). La comunicación interna en la universidad. Investigar para conocer a nuestros públicos. Revista Latina de Comunicación Social, 12(64), 262-274. https://doi. org/10.4185/RLCS-64-2009-822-262-274

Instituto Nacional de Estadística (2020). Encuesta sobre equipamiento y uso de tecnologías de información y comunicación en los hogares 2019. INE. https://www.ine.es/jaxi/Datos.htm?path=/t25/p450/ base_2011/a2019/I0/\&file=01001.px\#!tabs-grafico

Marcos, A. (18 de abril de 2020). La ciencia parada por el coronavirus. Agencia SINC. https://www.agenciasinc.es/Reportajes/La-ciencia-parada-por-el-coronavirus

Mateos, R., Gimeno, R. y Martínez, M. (2009). Presencia de estereotipos en los medios de comunicación: Análisis de la prensa digital española. ESIC. https://idus.us.es/handle/11441/77849

Menárguez, A. T. (14 de abril de 2020a). La mayoría de profesores españoles rechaza el aprobado general. El País. https://elpais.com/sociedad/2020-04-14/la-mayoria-de-profesores-espanolesrechaza-el-aprobado-general.html

Menárguez, A. T. (24 de mayo de 2020b). ¿Bajar los requisitos para obtener una beca tiene efectos en el rendimiento de los alumnos? El País. https://elpais.com/sociedad/2020-05-24/tiene-efectosen-el-rendimiento-de-los-alumnos-bajar-los-requisitos-para-obtener-una-beca.html

Ministerio de Ciencia e Innovación (2020). Universidades y covid-19. Ministerio de Ciencia e Innovación (es). https://www.ciencia.gob.es/portal/site/MICINN/menuitem. 8ce192e94ba842bea3bc811001432ea0/?vgnextoid=90a7653022801710VgnVCM1000001d0414 OaRCRD\&vgnextchannel=ace15fbb878f0710VgnVCM1000001d04140aRCRD

Montañés, E. (5 de abril de 2020). Miles de científicos parados y cientos de máquinas PCR arrinconadas por «una cuestión burocrática». $A B C$. https://www.abc.es/sociedad/abci-miles-cientificos-paradosy-cientos-maquinas-arrinconadas-cuestion-burocratica-202004052228_noticia.html

Munguia, P., Brennan, A., Taylor, S. y Lee, D. (2020). A learning analytics journey: Bridging the gap between technology services and the academic need. The Internet and Higher Education, 46. https://doi.org/10.1016/j.iheduc.2020.100744

Nieto, C. (2014). La imagen de la Universidad de Huelva en la prensa. Comparativa de los diarios «Huelva Información», "Odiel» y «El Mundo Huelva Noticias» (2002-2009) Huelva: Universidad de Huelva, Departamento de Educación. http://rabida.uhu.es/dspace/handle/10272/7947

Piña, R. (9 de abril de 2020). El Gobierno ha mantenido inutilizados un mes laboratorios disponibles para hacer test del coronavirus. El Mundo. https://www.elmundo.es/espana/2020/04/09/ 5e8e0f3421 efa0e8588b469e.html

Presidencia de Gobierno (2020). Prensa/Actualidad/Educación y Formación Profesional. Gobierno de España. https://www.lamoncloa.gob.es/serviciosdeprensa/notasprensa/educacion/Paginas/index. aspx

Resnick, M. (2002). Rethinking learning in the digital age. En G. Kirkman (Ed.), The global information technology report: Readiness for the networked world (pp. 32-37). Oxford: Oxford University Press. https://dam-prod.media.mit.edu/x/files/papers/mres-wef.pdf 
Sanmartín, O. R. (26 de mayo de 2020). Manuel Castells insta a 10 autonomías a bajar las tasas universitarias sin concretar una contrapartida económica. El Mundo. https://www.elmundo.es/ espana/2020/05/26/5ecd69fe21 efa064288b458d.html

Sánchez, B. y Moya, D. (2018). Nuevo soporte, nuevos medios, viejos dueños. Aproximación estructural a la prensa digital en España. En Comunicación y poder en la red. Casos de estudio y propuestas para el empoderamiento (pp. 29-44). Egregius.

Segura, C. (6 de abrilde2020). Laluchacontrael coronavirusfrenala investigación deotrasenfermedades. El País. https://elpais.com/ciencia/2020-04-06/la-lucha-contra-el-coronavirus-frena-la-investigacionde-otras-enfermedades.html

Silió, E. (14 de abril de 2020a). A 3.000 de mis estudiantes les está fallando la conectividad de forma habitual. El País. https://elpais.com/sociedad/2020-04-14/a-3000-de-mis-estudiantes-les-estafallando-la-conectividad-de-forma-habitual.html

Silió, E. (23 de abril de 2020b). Los rectores estiman que 36.000 universitarios tienen trabas técnicas para seguir las clases o examinarse. El País. https://elpais.com/sociedad/2020-04-23/los-rectoresestiman-que-36000-universitarios-tienen-trabas-tecnicas-para-ver-las-clases-o-examinarse.html

Silió, E. y Vallespín, I. (7 de mayo de 2020). Castells propone a las comunidades que rebajen las tasas universitarias, pero no concreta fondos extra. El País. https://elpais.com/sociedad/2020-05-07/ castells-propone-a-las-comunidades-que-rebajen-las-tasas-universitarias-pero-no-concretafondos-extra.html

Simón, P. (7 de junio de 2020). Odiar la educación. El País. https://elpais.com/opinion/2020-06-07/ odiar-la-educacion.html

Tejedor, S., Cervi. L., Tisa. F. y Parola. A. (2020). Educación en tiempos de pandemia: reflexiones de alumnos y profesores sobre la enseñanza virtual universitaria en España, Italia y Ecuador. Revista Latina de Comunicación Social, 78, 1-21.

Turcan, R. V. y Gulieva, V. (2016). University Internationalization and University Autonomy: Toward a Theoretical Understanding. En R. V. Turcan, J. E. Reilly y L. Bugaian (Eds.), (Re)Discovering University autonomy: The global market paradox of stakeholder and educational values in higher education (pp. 215-235). Palgrave Macmillan. https://doi.org/10.1057/9781137388728_15

Vallespín, I. (17 de mayo de 2020). Las universidades detectan 615 alumnos que no pueden seguir el curso online. El País. https://elpais.com/espana/catalunya/2020-05-17/las-universidades-detectan615-alumnos-que-no-pueden-seguir-el-curso-online.html

Verdaguer, J. (19 de abril de 2020). El profesor ante la cuarentena. El País. Cartas a la Directora. https:// elpais.com/elpais/2020/04/19/opinion/1587308726_632088.html

Vizoso, S. (23 de abril de 2020). Rebelión en Galicia contra la Universidad virtual. El País. https://elpais. com/sociedad/2020-04-23/rebelion-en-galicia-contra-la-universidad-virtual.html 